\title{
Özel Dosya: Gündelik Hayatta Etik ve Ahlak Sayı Editörlerinden
}

\author{
Yağmur Nuhrat, Gülay Uğur Göksel
}

Reflektif'in beşinci sayısındaki, “Gündelik Hayatta Etik ve Ahlak” başlıklı özel dosya, farklı biçimlerde tanımlamanın mümkün olduğu etik ve ahlak mefhumlarının çeşitli dayatmalar, muhasebeler, bir tarafta evrensel kabul edilen yargılar, diğer yanda öznel bağlılıklar ekseninde ve gündelik hayatta müzakere edilme biçimlerine odaklanıyor. Sayıdaki yazıların bazıları doğrudan bu müzakereleri ele alıyor; diğerleri ise söz edilen yapıları ya da kuralları konu ediyor. Biz bu sayıyı tasarlarken sosyal bilimlerin etik ve ahlaka ilişkin ortaya koyduğu çeşitli içgörülerden yola çıktık: İnsanlar yazılı, yazısız ahlak ve etik kurallarını ve kodlarını, farklı ölçeklerde kendilerinden talep edilen normatif beklentileri sürekli olarak değerlendirir ve bunlarla hesaplaşırlar. Açmazlara rağmen ve açmazlarla beraber anlatılar kurarlar. Bu konularda karşılıklı ve iç müzakereler sayesinde hem kendiliklerini kurmaya çabalar hem de kendilerine ve değer verdiklerine “iyi hayat”lar inşa etmek isterler. Öte yandan, bu “iyi” hayat”lar hem anlık anlatıların hem de hayat hikayesi anlatılarının gösterdiği üzere tutarsızlık, bitmemişlik ve bilinmezliklerle dolu olabilir. Etik ve ahlak müzakereleri parçalı olur, çelişkiler ve çatışmalar içerir. Bu çelişki ve çatışmalarla hesaplaşmak hiyerarşilerle ve iktidarla da hesaplaşmak anlamina gelir.

Bu sayıdaki birden çok makalenin vurguladığı gibi etik ve ahlak ilişkisel olarak, öznelerarası (intersubjective) kurgulanıyor, normatif ilkelerden çok toplumsal süreçlerle ortaya çıkıyor. Etik ve ahlak mefhumlarına getirilen bu ilişkisel bakış, evrensel kabul edilen yargı ve dayatmaların, müzakere süreçlerinde nasıl tutarsızlıklara ve yoruma açık olabileceğini gösteriyor ve hem toplumsal hem de kurumlar ve bireyler arasındaki politik boyuta dikkat çekiyor. Nitekim, bireysel zihinsel süreçler ya da soyut ilkeler bu ilişkiler sayesinde deneyimlenebiliyor yani insanların gündelik hayatıyla temas edebiliyor. Bu öznelerarasılık bazen bu konuda araştırma yapanı da içerebiliyor ve araştırmacının kendi konumunu sorgulamasına neden olabiliyor ya da buna izin verebiliyor. Durum, ihtimal ve bağlamlar insanların etik ve ahlak üzerinden değerlendirdikleri icraatlarında etkin oluyor. Böylece mutlak “iyi," ya da "doğru” dan söz etmek karmaşıklaşabiliyor. Bazı durumların kendisi etik ya da ahlak muhasebesini davet edebiliyor ya da engelleyebiliyor. Bu durum ve bağlamlardan hareketle toplumlar kendi etik/ 
ahlak dillerini ve lügatlarını oluşturuyorlar. "İyi," "doğru” ya da "adil” in yanına "onurlu," "hakkaniyetli," ya da "dürüst" sıralanıyor; daha niceleri türetilebiliyor.

Bu sayı felsefe, psikoloji, sosyoloji, medya, siyaset bilimi, iktisat, antropoloji, sinirbilim ve sinema alanlarından yani geniş bir disiplin yelpazesinden yazı içeriyor. Bu yazıların "etik," "ahlak" ya da "gündelik hayat" kavramsallaştırmaları, kuramla ilişkilenmeleri, varsayımları ve terminolojileri her zaman buluşmuyor. Öte yandan, bu giriş yazısında göstermeyi amaçladığımız gibi, birlikte okunduğunda sayıdaki yazıların ele aldığımız meselenin farklı uçlarından tuttuğunu, yukarıda anlattığımız içgörülerle nasıl temas ettiğini ve dolayısıyla da benzer mefhumlara muhtelif biçimlerde nasıl yaklaşabileceğimizi aydınlattı̆̆ını görüyoruz.

Bu sayıya gönderilen ilk yazıların felsefe alanından gelmesinin bir tesadüf olmadığını düşünüyoruz. Felsefe, elbette, yüzyıllardır etik ve ahlak kavramsallaştırmalarını tartı̧mak için donanım sunuyor. Nitekim birçok sosyal bilimci sonrasında başka açılımlar ortaya koysa da belli başlı felsefe kuramlarına referansla söze başlar. Kantçı deontolojik etik de bu referanslar arasında önde gelir. Ömer Albayrak makalesi bizlere Kantçı yaklaşımın her zaman temsil edildiği gibi olmayabileceğini, içinde başka nüans ve kavramsallaştırmalar barındırdığını hatırlatıyor. Kant'ın ahlak mefhumunda duyguların yeri olup olmadığını Schiller eleştirisi üzerinden tartışan Albayrak, bizlere Kant'ın ahlak yasasının "akıl ile temellendiğini” ancak insanın "akıldan ibaret bir soyutlamaya" indirgenmediğini anlatır. Kant'a göre duygulara sahip olmanın "ödev kavramına da sahip” olmak için gerekli olduğunu ancak bu bilincin ampirik değil zihin temelli olduğunu hatırlatır. Kant'ın "ahlaki duygular" kavramsallaştırmasının "ödev”le olan ilişkisine vurgu yapar. Böylece yazar, bugün ahlak ve etikten söz ederken şu ya da bu şekilde Kant'la hesaplaşması gereken sosyal bilimcilere ince ve ayrıntılı bir okuma sunmuş olur. Evrensel ahlak kuralları ve tikel olanın ahlak anlayışı arasındaki ilişkiyi ikircikli olarak kategorize etmek yerine duyguların biricikliğinin bile evrenselliğini kavramsallaştırmanın mümkün olduğunu öne süren bu makale ahlak psikolojisi alanındaki araştırmalarla da kuramsal bağ kurmamıza izin verir.

Sosyal bilimlere baktığımızda psikolojinin ahlak ve etiğe ilişkin yüklü külliyata sahip olduğunu görüyoruz. Nitekim sayının kuram odaklı katkıları da, felsefeye ek olarak, bu alandan geliyor. Onurcan Yılmaz ve Fatih Bayrak ahlak psikolojisinde 1930'lardan bu yana hakim olmuş kuram ve yaklaşımları özetler, birbiri ardından formüle edilen kuramların nerelerden beslendiğini, hangi paradigmalar içinden konuştuğunu ve nasıl eleştirildiğini anlatırlar; günümüz ahlak psikolojisindeki tartışmanın ayrıntılarını ve ileriye dönük patikaların ipuçlarını sunarlar. Yazarlar, ahlaki yargıların hem biyolojik hem çevresel etmenlerle şekillendiğini öne süren "etkileşimci paradigma" yı ele alır ve bu paradigmayı etraflıca tartışırlar. Yağmur Nuhrat'ın Onurcan Yılmaz ve Sinan Alper'le yaptı̆̆̆ söyleşide de dile getirildiği gibi ahlak psikolojisi bugün evrensel ve kültürel olanın nasıl ilişkilendiğini araştırır. "İnsan zihninin çalışma mekanizmasıyla" ilgilenir ve Sinan Alper'in dile getirdiği şu soruya cevap arar "tam olarak hangi durumlarda...hangi özelliklere sahip insanlar...nasıl karar alıyorlar ve bunun sonuçları nasıl oluyor?" Söyleşide de altı çizildiği gibi ahlak psikolojisinin "durum" kavramsallaştırması 
yukarıda söz ettiğimiz "durum" ve "bağlam” vurgusunu hatırlatır. Öte yandan, bir farkı da vardır. Ahlak psikolojisinde durumlar deneysel yöntemlerle kontrol edilir ya da kontrolsüzlüğü üzerinden sınanır. Yukarıda sayının yaklaşımından söz ederken değindiğimiz "durum” ve "bağlam" ise sosyo-politik konjonktür içinden bir durum okumasını kasteder.

Yine ahlak psikolojisi alanından sayıya katkı sunan Sevim Cesur'un savı bu farkla ilişkilenir. Cesur’a göre ahlak psikolojisinin gündelik hayatta "sıradan insanlar" in ahlak değerlendirmelerini anlamada yetersiz kaldığı yerler vardır. Yazar eksiklikler olarak "bağlam, kültür ve dil” $i$ vurgular ve bunların toplumsallığının ahlakla ilişkilenmesinden yeterince söz edilmediğini anlatır. Cesur "anlatı" (narrative) kavramına odaklanır ve eleştirdiği eksikliği gidermek için "ahlakın doğal kavramsallaştırılmasının” çalışılması, bunun için de insanların "hikayelerini” yani anlatılarını dinlemek gerektiğini öne sürer. Ek olarak, kendi çalışmalarından hareketle insanların ahlak ekseninde yaptığı müzakerelerin "kişiler arası ilişkilerle ilgili olduğunu" ortaya koyar. İlişkisellik, başka yazarlarımız tarafından da tartışılan ve bu sayıda öne çıkan vurgulardan birisidir.

Zeynep Talay Turner belki bireysel olarak tahayyül etmeye alışık olduğumuz otonomi mefhumunun ilişkisel olarak kavramsallaştırılabileceğini anlatır. Bu tartışma elbette yüzyıllardır farklı felsefe okullarınca ele alınmış ve farklı düzlemlerde aydınlanma aklına getirilen bir eleştiri olarak tezahür etmiştir. Talay Turner da makalesinde Nietzsche ve Spinoza'nın duyguların otonomi üzerindeki etkisine vurgu yapan Kantçı evrensel ve rasyonel ahlak eleştirisini anlatır ama buna ek olarak ayrıca feminist felsefecilerin bu filozoflardan nasıl ilham aldığını ve ilişkisel otonomi anlayışını nasıl şekillendirdiklerini tartışır. Böylece Kant'ın otonom ve rasyonel ahlaki kendiliğinden farklı olarak hem kendiliğin parçalı ve muğlak halini hatırlatır hem de feminist felsefecilerin bakış açısı sayesinde toplumsal ilişkilerden, dış etmenlerden, duygulardan, arzulardan ve niyetlerden ari bir otonomluk varsaymanın sakıncalı olduğunu öne sürer. Böylece otonomi kavramından (ve dolayısıyla kavramın felsefedeki yerinden) vazgeçilmemiş olur ama kavram dönüşür ve Talay Turner'ın deyimiyle "insanın toplumsal doğasını reddeden kendilik ve faillikle ilgili varsayımlarından kurtulmuş" olur. Otonomi bireyin kendi iç dünyasında birtakım evrensel ve rasyonel ahlaki çıkarımlarının bir sonucu olmaktan çıkar ve ilişkisel etik çerçevesinde gündelik karşılaşmaların etkisinin bireysel eyleme yansıdığı ve kendini geliştirdiği ilişkisel bir pratiğe dönüşür. Spinoza'nın etik tahayyülü sayesinde feminist felsefe hem ontolojik hem de etik olarak toplumsallı̆̆ımızı vurgular ve muhtelif ilişkiselliklerin etiğini hayal etmek için analitik bir donanımına sahip oluruz.

Talay Turner'ın felsefi boyutlarını araştırdığı ilişkisellik Kenan Çayır'ın kapsayıcı eğitim üzerine yazdığı yazıda örneklenir. Çayır, Milli Eğitim Bakanlığı’nın kapsayıcı eğitim kavramsallaştırmasının bir taraftan "insan hakları" gibi evrenselci bir dille formüle edildiğini, öte yandan ise buna zıt düşen "fütüvvet" ve "ahilik" gibi etno-dinsel ve yerel kavramlarla temellendiğini anlatır. Bu makale evrensel "insan hakları" ilkesinin, ulusal düzeyde onu yorumlayanlar tarafından nasıl tekrar tanımlandığını ve bu tanımın resmi düzeyde farklılıkları içermek yerine dışlamak için nasıl kullanılabileceğini gösterir. Bu iki farklı temellendirmenin 
arasındaki çelişki, bu çelişkinin kapsayıcılık gibi bir amacı ortaya koymak için birlikte ama çatışan biçimde var olma hali etik ve ahlakın gündelik hayattaki muğlak varoluşuna çarpıcı bir örnektir. Çayır bu iki formülasyonun da ötesinde bir sav kurar. Normatif evrenselci bir "hak" yaklaşımını benimsemektense, tam da kapsayıcılığın nasıl müzakere edildiğine ışık tutabilecek olan "ilişkisel kapsayıcılık" yaklaşımını önerir. Bizlere "hak kavramı[nın] da, etik ve ahlaki olanın da toplumsal aktörlerin arasındaki gerilimlerle, mücadelelerle ve müzakerelerle şekillen[diğini]" hatırlatır. Buradan hareketle, etik ve ahlak çerçevesinde bir amaç olarak adlandırabileceğimiz kapsayıcılığın toplumsal aktörlerin ilişkilerinden bağımsız hayal edilemeyeceğini, bu ilişkiler bağlamında ve sayesinde kurulup ayakta tutulabileceğini savunur.

Yukarıda etik ve ahlakın sahada kendi lügatları olabileceğinden söz etmiştik. Şüphesiz ki "hak" ve "hakkaniyet" sözcükleri ve mefhumları Türkiye sahası için buna birer örnek. Çayır makalesinde de ele alınan bu kavramlar, Yusuf Yüksekdağ ve Sernaz Arslan makalelerinde derinlemesine işlenir. Yusuf Yüksekdağ yazısında sığınmacıların medya temsillerine odaklanır; temsilde "etik odaklı" bir çerçeve önerir ve bunun da "hak temelli" bir bakış açısıyla mümkün olabileceğini öne sürer. Bu makalede daha evrenselci bir "insan hakları" vurgusu olmakla beraber, bu mefhumun başka normlarla çelişki ya da çatışma içinde olabileceğinin altı çizilir. Yani hem bu sayının çağrısında hem de yukarıda dile getirdiğimiz farklı normatif dayanakların teması ve bu temastan hareketle yapılan seçimlerin tezahürleri bu makalede örneklenmiş olur. Yüksekdağ makalesi, isminden de anlaşılacă̆g gibi, temsil meselesine dikkat çeker. Yazar "acı çeken" temsilinin, bu temsile maruz kalanda yarattı̆̆ı sorumluluğu ya da yükümlülügü sorgular. Burada "yardım" ve "sorumluluk" arasındaki normatif farka işaret eder.

Sernaz Arslan ise yine "hak" üzerinden ama bu sefer Lefebvre'nin "kent hakkı" kavramsallaştırmasını genişletmeyi hedefleyerek bir tartışma sunar. Kent hakkı üzerine çalışan başka bazı araştırmacılar gibi Arslan da Lefebvre'in kavramsallaştırılmasının sınıfsal boyuta odaklanıyor olmasını yetersiz bulur. Kentin karmalı̆̆ını paylaşan ve özellikle dezavantajlı konumda olan kentlilerin, örneğin evsizlerin, kent hakkını düşünmek gerektiğini vurgular. Bunun da bir adım ötesinde, hangi grupların neden ötürü ve nasıl kent hakkından mahrum edildiklerinin araştırılması gerektiğini savunur. Aksi takdirde, "kent hakkı" ifadesinin bir slogandan öteye gidemeyeceğini belirtir. Böylelikle Arslan'ın yazısı bizi, tıpkı Çayır ve Yüksekdă̆ makaleleri gibi, "hak" mefhumunun, bu sefer kent üzerinden, nasıl müzakere edilebileceğini düşünmeye çağırır. Bizlere bu müzakerenin aktörlerinin kimler olduğunu, onların önceliklerini ve iktidarla ilişkilenmelerinin nasıl olduğunu merak ettirir. Kenti "ev" edinenlerin evsizliği üzerinden, yukarıdaki kapsanma ve temsil edilme sorunsallarına benzer biçimde bir hak iddia etme kaygisına dikkat çeker.

Bu makalelerde olduğu gibi "hak" kavramını sorgulayan ve çelişen normatif kurguların ilişkisini değerlendiren bir diğer katkı Deniz Nihan Aktan'nın makalesidir. Aktan, sporun Eski Yunan'dan bu yana çeşitli toplumsal ve siyasi evrelerinde, fiziksel rekabetin ahlak çerçevesini nasıl kurduğunu anlatır ve sosyokültürel antropolojinin 2000'lerdeki etik dönüşü sonrasındaki yaklaşımının temel bir öğretisini benimser: Etik ve ahlak birer toplumsal yansıma ya da 
kendinden menkul kategoriler değildir. Aksine etik ve ahlak toplumsallığın kurucu etmenlerindendir ve topluma bütünüyle nüfuz ederler. Aktan bize geriye dönük bir dizi alternatif okuma sunar. Etik ve ahlak formatif, ilişkisel ve öznelerarası anlaşıldığında ve gündelik hayatta müzakere edilen ögeler olarak değerlendirildiğinde spor üzerinden çeşitli sosyo-politik konjonktürlerde "hakkaniyet" okumanın nasıl çeşitlenebileceğini gösterir. Muhtelif hakkaniyet kavramlarının ve adil oyun (fair play) standardının nasıl temas halinde olabileceği, neoliberal kapitalist etik kavramsallaşması, "hak temelli" yaklaşımın ve sınırlı biçimde kurgulansa da "kapsayıcılığın" bir arada var oluşu yani çatışan normatif bilgi bütünlerinin ilişkisi üzerine düşünmemiz gerektiğini vurgular.

Talay Turner'dan kendiliğin parçalı haline ilişkin felsefi içgörüyü aldıktan, birçok yazarımızdan da "hak" kavramsallaştırması üzerine okuduktan sonra, sosyal bilimlere belki ilk bakışta uzak görünse de bu sayının tartışmak istediği konuları doğrudan masaya yatıran bir sinirbilim makalesine geçiyoruz. Tugay Keçeci ve Işın Çolak nöroteknolojideki gelişmeler ve nöroetik arasındaki ilişkiyi anlattıkları makalelerinde bizlere temel bir gerilim ve buradan hareketle de yeni kavramlar sunarlar: İnsan hayatını iyileştirmek ve arazlarını tedavi etmek için kullanılan sinirbilim yöntemlerinin o aynı insanın kişiliğini, hafızasını, zekasını ya da duygularını değiştirme ihtimali varsa, bu ne derece kabul edilebilir bir müdahaledir? Sinirbilimdeki bu "nöroetik" ve "nörohukuk" tartışmaları bizi "nörohak" mefhumuna götürür ve hakim olduğumuzu sandığımız "insan hakları" çerçevesini yeniden düşünmeye iter. Yani aslında sosyal bilimlerin birçok alanında bugün "evrenselciliğinin" indirgemeci olduğu öne sürülen "insan hakları" olgusu evrenselliği açısından da sorgulanmış olur. Yazarlar ayrıntılandırdıkları bu tartışmalara kendilik ve beyin arasındaki bağlantıya ilişkin varsayımlarımızı sorgulayan, Ömer Albayrak makalesini de hatırlatan, varoluşsal bir soru da eklerler ve bu soruyu insan-makine kümlenmelerini hatırlatarak karmaşıklaştırırlar. Sonuç olarak tıp etiğinin içinde "özel bir yeri” olan nöroteknoloji ve nöroetik gerilimi bizlere açmazlar, ödünlemeler ve karar verme mekanizmaları üzerine düşünmek için zemin sağlar ve buradan hareketle de insanın kendiliğini ve haklarını kavramsallaştırmaya ilişkin doğrudan malzeme sunar.

Etik ve ahlakın sahadaki tezahürü ve dili açısından önemli bir hatırlatma da yukarıda söz ettiğimiz Sevim Cesur makalesinde sunulur. Cesur, kuramların buna değinmemesine rağmen "dürüstlük" kavramının "sıradan insanın hayatında" önemli olduğunu anlatır. Ayça Ebru Giritligil'in iktisatta “yalan” üzerine düşündüğü ve yalanı çok boyutlu biçimde tartışttğı görüş yazısı da bu kavramla doğrudan ilintilidir. Yalana ve yalan söyleme davranışlarına yine farklı disiplinler farklı yaklaşmaktadır. Örneğin sosyoloji ya da antropoloji bugün yalanın söylenip söylenmediğinden ziyade, söylendiği durumlardaki alt metinleri, sosyokültürel kodları hatta hakikatin bu kodlarla birlikte ve öznel biçimlerde nasıl farklı şekillenebileceğini araştırır. Giritligil ise yalanı daha nesnel ve sosyal ve ekonomik zarara yol açtığı için her koşulda önlenmesi gereken bir davranış olarak ele alır. Bununla birlikte, "standart iktisat teorisinin" yalan söyleme davranışına ilişkin varsayımlarını sorgular ve bunlarla çelişen bulgular sunar: insanlar kendi maddi çıkarlarını arttırmak için dahi yalan söylemeyebilir; yalanın "getirisinin 
ve maliyetinin" karmaşık maddi ve manevi bileşenleri vardır. Bu karmaşanın çözümlenmesi hem sosyal bilimlerin üstlendiği toplumu derinlemesine anlama misyonuna hem de Giritligil'in vurguladığı "zarar" In azaltılmasina hizmet edecektir.

Açmazlar, gerilimler ve hukuk üzerine düşünen ve bu sefer sanat alanından sunulan, bir başka yazıda Selman Nacar ve Feride Çiçekoğlu'nun Nacar'ın filmleri, özellikle de son filmi İki Şafak Arası'nda üzerine yaptıkları söyleşiyi okuruz. Nacar hem bu söyleşide hem de Reflektif için İstanbul Bilgi Üniversitesi’nde düzenlenen özel gösterimde ifade ettiği gibi, “ahlak-etik-hukuk" meselesini ve bu üç bilgi bütünü ya da kurgu arasındaki gerilimi filmin merkezine alır. Filmde, fabrikasındaki bir iş kazasından sonra tam da bu gerilim ekseninde karar verme, çeşitli kurum ve aktörlere hesap verme ve kendiliğini kurmaya çalışan Kadir karakterini izleriz. Nacar'ın deyimiyle bu gibi süreçler bir "ahlak-hukuk çatışması" içerir ve kendimizle ya da birlikte yaşayabilmek için yapmamız gereken seçimler vardır. Nacar seçimin ne olması gerektiğini dayatmaz; seçim anlarının içerdiği çoğulluğu ve zenginliğini, Çiçekoğlu'nun da ifade ettiği gibi o "gri alanları" sanatla anlatmak ister. Ek olarak, izleyicinin kendini Kadir yerine koyup "ben olsam ne yapardım?” diye sormasını çağırır.

Bu çağrı, yani sanatçının izleyiciyi kurduğu karakterden hareketle bir ahlak muhasebesine davet etmesi Yağmur Nuhrat'ın görüş yazısına bağlanır. Nuhrat etik ve ahlak konularını mesele eden etnografik araştırması sırasında görüştüğü insanları etik ve ahlak üzerinden muhasebe ve müzakereye çağırdığını fark eder. Butler üzerinden çözümlediği bu çağırma ya da celp etme halini özdüşünümsel ve yöntembilimsel açlardan ve araştırma etiği çerçevesinde tartışır. Yazısında "muhtelif çağrılar, çağıranların da muhtelif konum ve faillikleri" olduğunu ifade eder. Böyle bakıldığında Nacar'ın ve Nuhrat'ın çağrılarını karşılaştırmak mümkündür. Bir sinemacının izleyiciyi vicdan muhasebesine, yani "ben olsaydım ne yapardım?" sorusuna çağırması ve bir antropologun birlikte çalıştı̆̆ katılımcıları bir etik/ahlak değerlendirmesine davet etmesi birlikte nasıl düşünülebilir? Nuhrat'ın söz ettiği muhtelif çağrılara Yüksekdağ'ın yazısı da eklenebilir. Acının medya temsili bunu gören için nasıl bir etik çağrıdır? Nasıl bir sorumluluktur?

Reflektif yayın girdiği günden bu yana disiplinlerarası bir dergi olmayı hedefledi. Çeşitli toplantılarda, bunun iki yolu olabileceği etraflıca konuşuldu ve tartışıld. Bir yolu yayınlanan yazıların kendi doğaları itibarıyla disiplinlerarası olmasıydı. Diğer yolu ise derginin birden çok disipline ev sahipliği yapması ve özel dosyalar sayesinde bu disiplinlere konuşacak alan açmasıydı. Bu sayı ikinci formülün bir örneği. Etik ve ahlak, burada da açıkça görüldüğü gibi, sinemadan sinirbilime, felsefeden iktisata birçok alanı bağlıyor. Yaklaşımların ve varsayımların buluşması ya da çatışmasına şahit olmanın okuyucularımızı heyecanlandıracağını umuyoruz. 